Proceedings of the IX International Conference ION 2012, Kazimierz Dolny, Poland, June 25-28, 2012

\title{
Polymeric Track Etched Membranes - Application for Advanced Porous Structures Formation
}

\author{
B. Sartowska ${ }^{a, *}$, W. Starosta ${ }^{a}, \mathrm{P} \cdot \mathrm{Apel}^{b}, \mathrm{O} \mathrm{Orelovitch}^{b}$ And I. Blonskaya $^{b}$ \\ ${ }^{a}$ Institute of Nuclear Chemistry and Technology, Dorodna 16, 03-195 Warsaw, Poland \\ ${ }^{b}$ Flerov Laboratory of Nuclear Reactions, Joint Institute for Nuclear Research \\ Joliot-Curie 3, 14198 Dubna, Russia
}

\begin{abstract}
Track etched membranes are porous systems consisting of a thin polymer foil with channels from surface to surface. Latent ion tracks are the result of the passage of swift ions through solid matter and they can be etched selectively. As a result, conical, cylindrical or other shape channels can be obtained. The increasing interest in the polymer track etched membranes with nanochannels is connected with development and creation of nanoporous materials of unique properties. The template synthesis method based on deposition of materials inside well-defined uniform pores of membranes offers unique possibilities of formation of one-dimensional, high aspect ratio (length to diameter) cylindrical species having form of rods, wires, tubules, multiwall tubules and multilayer rods, practically from any solid material. Metal-organic frameworks are a class of hybrid materials comprising metal ion-based vertices and organic ligands (linkers) which serve to connect the vertices into one-, two- or three-dimensional periodic structures. A specific property of porous structures is their intrinsic porosity, which renders them potentially useful for gas storage, separation and catalysis. The possibility of obtaining a new composite material: polymeric track etched membrane with pores filled with hybrid porous material has been demonstrated.
\end{abstract}

DOI: $10.12693 /$ APhysPolA.123.819

PACS: 61.82.Pv, 81.16.Be, 81.05.Rm, 61.43.Gt

\section{Introduction}

Track etched membranes are porous systems consisting of a thin polymer foil with channels - pores — from surface to surface. Membranes production is well-known and described in literature [1-5]. The energetic ions create changes in a material along their trajectory when they travel through the material. These changes, structural and/or chemical, alter the material properties. They deposit energy in material and they cause radiation damage. The polymeric chain or network can be cleaved. These regions can be chemically attacked [3]. During chemical etching the damaged zone of a latent track is removed and transformed into a hollow channel. It is the pore-size-determining and pore-shape-determining stage of the technology. The simplest description of pore geometry is based on two parameters - the bulk etch rate $V_{\mathrm{B}}$ and the track etch rate $V_{\mathrm{T}}$. It is applicable for larger pores ( $\geq 1 \mu \mathrm{m}$ in diameter) (Fig. 1a). The conical pore shape is transformed into a cylindrical one at $V_{\mathrm{T}} \gg V_{\mathrm{B}}$. The geometry of smaller pores is determined also by the size and structure of the damaged zone around the particle path (Fig. 1b), where $d_{\mathrm{c}}$ and $d_{\mathrm{h}}$ are the diameters of core and halo of the pore, respectively. The bulk etch rate depends on: the material, etchant composition and temperature. The track etch rate depends on a greater number of factors, like: material sensitivity, irradiation conditions, post-irradiation conditions and etching conditions. To increase the track etching rate, various meth-

* corresponding author ods of sensitisation are used: oxidisation with oxygen from air, photo-oxidation and action of different solvents $[2,3,5]$. The scheme of membranes' process production is presented in Fig. 2 and shows all its parts: ion irradiation, sensitisation and chemical etching.
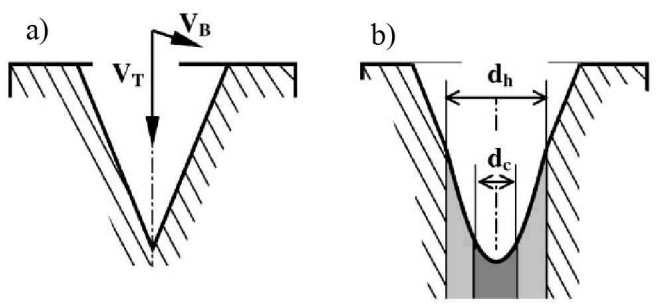

Fig. 1. Scheme of pore formation: (a) etched pore geometry, (b) pore shape on a submicroscopic scale.

The increasing interest in the polymer track etched membranes with nano-channels is connected with development and creation of nanoporous materials of unique properties, for example: development of nanoporous materials with highly asymmetrical nanopores for molecular sensors, study of propagation of X-rays and acoustic waves through track-etched membranes as a model of porous medium, development of nanocapillary bodies for modelling the transport of molecules and ions in constrained volumes.

The template synthesis method based on deposition of materials inside well-defined uniform pores membranes offers unique possibilities of formation of one-dimensional, high aspect ratio cylindrical species having a form of rods, wires, tubules, multiwall tubules and mul- 


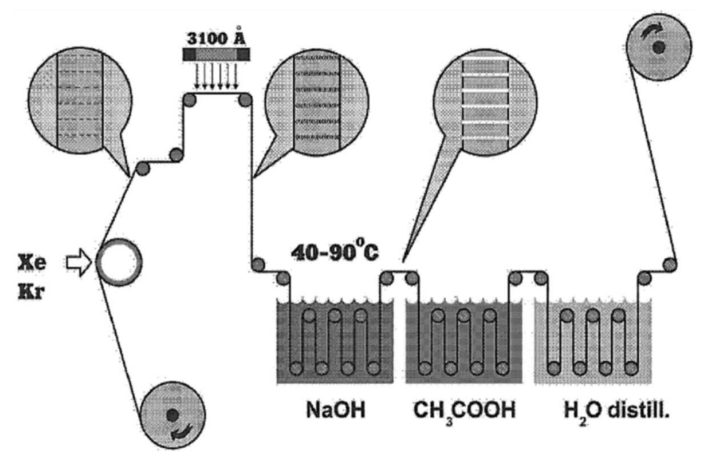

Fig. 2. Scheme of membrane production process showing all parts: ion irradiation, sensitisation and chemical etching.

tilayer rods, practically from any solid material like metals and alloys, semiconducting materials, carbon, metal oxides and polymers [6, 7]. Rapidly growing interest in the template based synthesis is the result of search for novel methods of manufacturing materials with predefined shapes and dimensions in nanorange. It is expected that high aspect ratio objects will find application in many areas of technologies (biotechnology, catalysis, optoelectronics, microelectronics, microcomputers etc.) in the nearest future. Different deposition methods for filling the pores can be applied, e.g. electrochemical deposition, electroless deposition, layer-by-layer self-assembly, sol-gel deposition [8, 9].

Metal-organic frameworks (MOFs) are a class of porous hybrid materials comprising metal ion-based vertices and multitopic organic ligands (linkers) which serve to connect the vertices into one-, two- or three-dimensional periodic structures. The possibility of combining a wide range of metals with a similarly large number of available ligands opens ways to design the structures meeting specific purposes [10]. The structures and properties of hybrid porous material can be tailored. A specific property of porous structures is their intrinsic porosity. Metal-organic frameworks materials have recently attracted intense research interest because of their porous structures, big surface area, and potential application as novel adsorbents and catalysts. Interest in these materials has been driven by a possible use for greenhouse gases removal, hydrogen storage for future clean energy technologies, and for highly selective separation of gaseous mixtures $[11,12]$. At present, many potential applications of porous structures may require them to be constructed at the nanometre length scale [13].

The well-known copper(II) benzene-1,3,5-tricarboxylate $\mathrm{Cu}_{3}(\mathrm{BTC})_{2}\left(\mathrm{H}_{2} \mathrm{O}\right)_{3}$ (BTC - benzene-1,3,5-tricarboxylate) compound, called HKUST-1 forms a face-centered cubic crystalline framework that is composed of dimeric cupric tetracarboxylate units. It gives an intersecting $3 \mathrm{D}$-channel system with a micropore diameter of $0.7-0.8 \mathrm{~nm}$. Langmuir surface area of HKUST-1 is about $2200 \mathrm{~m}^{2} / \mathrm{g}$.
The aim of this work was to obtain a new composite material: polymer track etched membrane with pores filled with hybrid porous material. Such composite membranes can find application in sensing and removal of harmful gases, particularly gaseous radioactive species released during nuclear fuel reprocessing or in the case of nuclear accidents.

\section{Experiment}

Polyethylene terephthalate (PET) film with a thickness of $12 \mu \mathrm{m}$ was irradiated with $250 \mathrm{MeV} \mathrm{Kr}$-ion beam with the ion fluency of $2 \times 10^{7} \mathrm{~cm}^{-2}$. The standard etching procedure $\left(\mathrm{NaOH}\right.$ solution as the etchant, $\left.60^{\circ} \mathrm{C}\right)$ was applied. As a result the membrane with cylindrical pores with a diameter of $1.2 \mu \mathrm{m}$ was obtained and was taken as a matrix for the template synthesis of hybrid porous material. HKUST-1 has been selected for deposition inside the pores of track-etched membranes. Synthesis of HKUST-1 has been performed by the solvothermal method described in detail in [14]. Droplets of prepared solution were deposited on the surface of plasma activated PET track-etched membrane with a pore diameter of $1.2 \mu \mathrm{m}$. Characterisation of pores and composite material (membrane with the pores filled with hybrid porous structures) were carried out using scanning electron microscopy (SEM) including high resolution SEM (HR SEM) with DSM 942 (Zeiss, Germany) and GEMINI 1530 (Zeiss, Germany). The special method of samples' fracture preparation was developed and used for SEM studies [15]. Elemental composition of porous nanostructures obtained at the surface of membrane was determined using the energy dispersive spectroscopy (EDS) technique with Quantax 400 (Bruker, Germany). Structure determination of the synthetized compounds were carried out using the Xcalibur-R single crystal diffractometer.

\section{Results and discussion}

The surface and fracture of the PET membrane are presented in Fig. 3. It can be clearly seen that pore mouths were round shaped. Their statistically calculated diameter was $1.2 \pm 0.1 \mu \mathrm{m}$. The pore distribution determined from the SEM images was $2 \times 10^{7} \mathrm{~cm}^{-2}$ (Fig. 3a). It can be seen in the fracture of the membrane body that pores are of cylindrical shape and perpendicular to the surfaces (Fig. 3b). The thickness of the obtained membrane was $9.0 \mu \mathrm{m}$ as a result of both side polymer etching process with bulk etch rate $V_{\mathrm{B}}$. This membrane was used as a template for the template synthesis.

As a result of solvothermal synthesis processes, the blue powder samples were obtained. The SEM images reveal a mixture of crystalline material having a broad range of dimensions. Octahedral grains/crystallites with the sizes of about $100 \mu \mathrm{m}$ (the largest ones) are presented in Fig. 4a. The SEM photograph shown in Fig. 4b revealed the presence of octahedral, nanoscale crystals with 


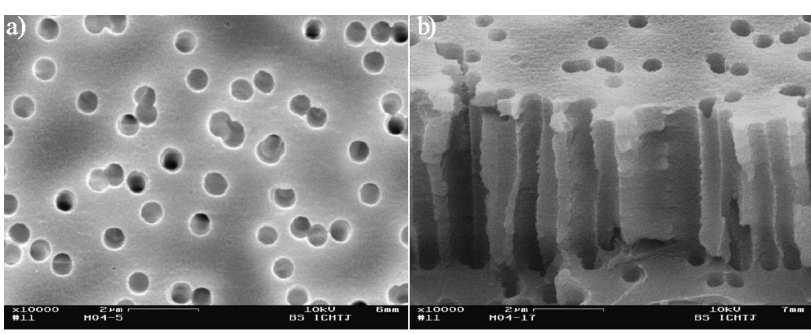

Fig. 3. Polymeric (PET) track etched membrane: (a) surface, (b) fracture.

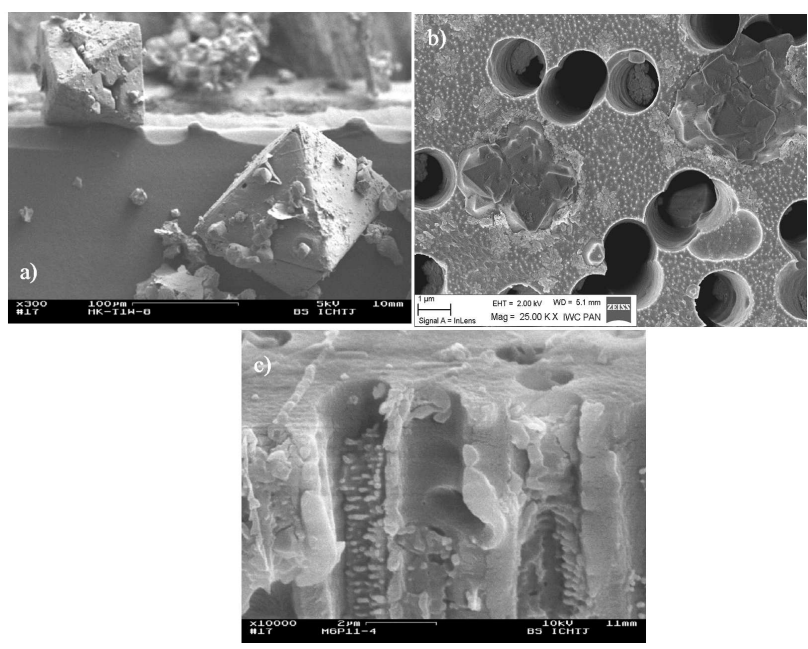

Fig. 4. Synthetized HKUST-1: (a) crystallites with different dimensions, (b) PET membrane surface with octahedral in shape, nanoscale crystals, (c) pores filled with hybrid porous material.

the dimensions below $1 \mu \mathrm{m}$ filling the fraction of the pores of membrane used as a matrix for template synthesis. Small octahedral, blue coloured single crystal has been selected from the reaction product for structure determination. The measurements confirmed the presence of face centred cubic structure of $\mathrm{Cu}_{3}(\mathrm{BTC})_{2}\left(\mathrm{H}_{2} \mathrm{O}\right)_{3}$, with the lattice parameter $26.346 \AA$. The fracture of membrane after the template synthesis was carefully observed (Fig. 4c). One can clearly see that there was the deposit inside the pores of used membranes. This deposit filled the channels and formed small grains of the sizes in the range of $0.24-0.59 \mu \mathrm{m}$.

The EDS spectra taken from the surface of membrane show characteristic peaks of X-ray. The quality and quantity analyses allowed us to determine the elemental composition of the deposit. The obtained results were as follows (in wt\%/at.\%, respectively): $\mathrm{Cu}-35.0 / 11.2$;
$\mathrm{C}-24.3 / 41.1$ and $\mathrm{O}-37.2 / 47.3$. These results confirm that HKUST-1 was synthesized.

\section{Conclusions}

1. Polymeric track etched membranes with the pores diameter of $1.2 \mu \mathrm{m}$ and the pores density of $2 \times 10^{17} \mathrm{~cm}^{-2}$ were obtained by PET foil irradiation with accelerated $250 \mathrm{MeV} \mathrm{Kr-ions} \mathrm{and} \mathrm{chem-}$ ical etching.

2. The possibility of obtaining a new composite material: polymeric track etched membrane with pores filled with hybrid porous material, using the template synthesis method, has been demonstrated.

\section{References}

[1] R. Spor, Nucl. Tracks 4, 101 (1980).

[2] P.Yu. Apel, Radiat. Measur. 34, 559 (2001).

[3] W. Ensinger, R. Sudowe, R. Brandt, R. Neumann, Radiat. Phys. Chem. 79, 204 (2010).

[4] P.Yu. Apel, I.V. Blonskaya, S.N. Dmitriev, T.I. Mamonova, O.L. Orelovitch, B. Sartowska, Yu. Yamauchi, Radiat. Measur. 43, S552 (2008).

[5] P.Yu. Apel, I.V. Blonskaya, T.W. Cornelius, 1, R. Neumann, R. Spohr, K. Schwartz, V.A. Skuratov, C. Trautmann, Radiat. Measur. 44, 759 (2009).

[6] A. Huczko, Appl. Phys. A 70, 365 (2000).

[7] S. Hou, C.C. Harrell, L. Trofin, P. Kohli, C.R. Martin, J. Am. Chem. Soc. 126, 5674 (2004).

[8] N.I. Kovtyukhova, T.E. Mallouk, T.S. Mayer, Adv. Mater. 15, 780 (2003).

[9] W. Starosta, M. Buczkowski, B. Sartowska, D. Wawszczak, Nukleonika 51, 535 (2006).

[10] Special issue on metal-organic framework materials, Chem. Soc. Rev. 38, 1201 (2009).

[11] S. Cavenati, C.A. Grande, A.E. Rodrigues, Ind. Eng. Chem. Res. 47, 6333 (2008).

[12] A.U. Czaja, N. Trukhan, U. Muller, Chem. Soc. Rev. 38, 1284 (2009).

[13] A. Carné, I. Carbonell, I. Imez, D. Maspoch, Chem. Soc. Rev. 40, 291 (2011).

[14] W. Starosta, B. Sartowska, K. Eyczko, J. Maurin, A. Pawlukojć, L. Waliś, M. Buczkowski, Nukleonika 57, 581 (2012).

[15] O.L. Orelovitch, P.Yu. Apel, B. Sartowska, J. Microsc. 224, 100 (2006). 